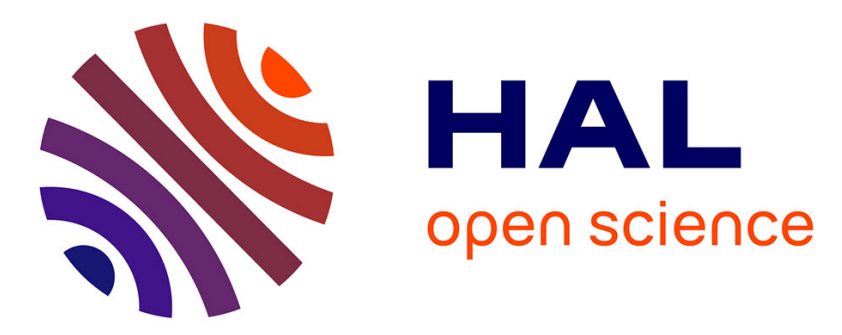

\title{
Day-Ahead Management of Smart Homes Considering Uncertainty and Grid Flexibilities
}

Carlos Adrian Correa-Florez, Andrea Michiorri, Alexis Gerossier, Georges

Kariniotakis

\section{- To cite this version:}

Carlos Adrian Correa-Florez, Andrea Michiorri, Alexis Gerossier, Georges Kariniotakis. Day-Ahead Management of Smart Homes Considering Uncertainty and Grid Flexibilities. 11th Mediterranean Conference on Power Generation, Transmission, Distribution and Energy Conversion, MEDPOWER 2018, Nov 2018, Dubrovnik (Cavtat), Croatia. hal-01948634

\section{HAL Id: hal-01948634 \\ https://hal.science/hal-01948634}

Submitted on 7 Dec 2018

HAL is a multi-disciplinary open access archive for the deposit and dissemination of scientific research documents, whether they are published or not. The documents may come from teaching and research institutions in France or abroad, or from public or private research centers.
L'archive ouverte pluridisciplinaire HAL, est destinée au dépôt et à la diffusion de documents scientifiques de niveau recherche, publiés ou non, émanant des établissements d'enseignement et de recherche français ou étrangers, des laboratoires publics ou privés. 


\title{
Day-Ahead Management of Smart Homes Considering Uncertainty and Grid Flexibilities
}

\author{
Carlos Adrian Correa-Florez, Andrea Michiorri, M IEEE, Alexis Gerossier, Georges Kariniotakis, SM IEEE
}

\begin{abstract}
This paper presents an optimization model for Home Energy Management Systems from an aggregator's standpoint. The aggregator manages a set of resources such as PV, electrochemical batteries and Thermal Energy Storage by means of Electric Water Heaters. The resources are managed in order to participate in the day-ahead energy market, considering also local flexibility needs. The resulting model is a mixed-integer linear programming problem in which the aim is to minimize dayahead operation costs for the aggregator while complying with DSO flexibility constraints in the form of maximum allowed net power exchange and ramping limits. Three sources of uncertainty are considered: day-ahead energy prices, $P V$ production and load. Kernel Density Estimator and a backward reduction algorithm are used to create price scenarios and Robust Optimization is used to model PV and load uncertainties. The obtained results show the changes in the operation of the aggregator when grid flexibilities are considered and the impacts on the operation costs. In addition, a proposal for bidding in local flexibility markets is shown.
\end{abstract}

Index Terms-Smart homes, Storage, Robust optimization, Battery cycling, Uncertainty.

\section{NOMENCLATURE}

Marker to identify central forecasts index for household, $h=1,2, \ldots, N$ index for scenario, $s=1,2, \ldots, S$ index for time step, $t=1,2, \ldots, T$

$\bar{H}_{h} \quad$ TES device maximum power [kW]

$\bar{P}_{h}^{\text {ch }} \quad$ Battery's maximum charging power [kW]

$\bar{P}_{h}^{h}$ Battery's maximum discharging power [kW]

$\bar{X}_{h} \quad$ Battery's maximum SOC [kWh]

$\bar{Y}_{h} \quad$ TES device maximum SOC [kWh]

$\eta^{c} \quad$ Battery's charging efficiency

$\eta^{d} \quad$ Battery's discharging efficiency

$\Gamma \quad$ Robustness parameter

$\pi_{t} \quad$ Spot price [EUR/kWh]

$\underline{X}_{h} \quad$ Battery's minimum SOC [kWh]

$\underline{Y}_{h} \quad$ TES device minimum SOC [kWh]

$C_{h} \quad$ Thermal capacitance of TES device

$D_{t, h} \quad$ Electrical load

$D_{t, h}^{q \%} \quad$ q-th quantile Electrical load

$Q_{t, h, s} \quad$ EWH load [kW]

$R_{h} \quad$ Thermal resistance of TES device

$H_{t, h} \quad$ EWH input $[\mathrm{kW}]$

Authors are with MINES ParisTech, PSL-Research University, PERSEE, Processes, Renewable Energies and Energy Systems, 06904 Sophia Antipolis, France. carlos-adrian.correa_florez@mines-paristech.fr. This work was carried out as part of the research and innovation project SENSIBLE (Storage ENabled SustaInable energy for BuiLdings and communitiEs - www.h2020 projectsensible.eu), which has received funding from the European Union under the Horizon 2020 Framework Programme grant agreement No 645963.

\author{
$P_{t, h}^{\mathrm{c}} \quad$ Battery charging power $[\mathrm{kW}]$ \\ $P_{t, h}^{\mathrm{d}} \quad$ Battery discharging power [kW] \\ $P_{t}^{\text {pcc }} \quad$ Maximum allowed power at the PCC $[\mathrm{kW}]$ \\ $P_{t}^{g} \quad$ Day-ahead energy commitment in the wholesale mar- \\ ket $[\mathrm{kWh}]$ \\ $u_{t, h} \quad$ Binary variable. Equals " 1 " if battery is charging, " 0 " \\ otherwise \\ $X_{t, h} \quad$ Battery SOC [kWh] \\ $Y_{t, h} \quad$ SOC of TES device \\ $z, q, y$ Dual and auxiliary variables of the robust counterpart
}

\section{INTRODUCTION}

In order to face the challenges raised by contemporary power systems, new approaches featuring decentralized generation and coordination with demand side flexibility have gained substantial attention in recent years. Some of these new schemes are being developed in the medium and low voltage grid, and most recently at building and home levels, leading to the development of concepts such as Smart Residential Buildings (SRB) and Home Energy Management Systems (HEMS) [1].

The research presented in [2] analyzes a microgrid composed by dispatchable units, one solar unit, one wind generator, one energy storage and adjustable loads. These resources are optimally scheduled so that minimum cost is achieved, while taking into account distribution net ramping in the model. These constraints act as a service required by the utility, leading to a cost increase in operation of the microgrid. However, this study disregards uncertainty and considers resources and load from a broad perspective without detailing buildingor home-level integration.

Reference [3] presents a two-stage optimization problem for day-ahead management of residential demand response resources. The model includes thermal load and also electrothermal storage, which can generate or consume power. Although this research does not consider batteries, renewable energy integration or utility interactions, it proposes an interesting model for generic electro-thermal technologies and their aggregation for exploitation of storage capabilities.

The work presented in [4] also integrates electric and thermal demand interaction, wind and solar generation, and uses Model Predictive Control (MPC) to capture uncertainty in renewable generation. Energy balancing is taken into account to minimize the interaction with the grid.

Another recent study [5] presents a comprehensive approach for the design and operation of an LV microgrid, taking into account active and reactive power, electric vehicles, voltage 
constraints, electric and thermal loads, and minimizing the system's $\mathrm{CO}_{2}$ emissions. Although this work does not consider uncertainties, batteries and other types of signals sent by the utility, it establishes an interesting benchmark for future microgrid studies.

The increasing attention in distributed resource management, also pushes DSOs and TSOs to request flexibility based on decentralized approaches. In the case of DSOs, local balancing and RES generation matching, open the possibility for local flexibility trading. These trends justify the need for management tools that lead towards distribution-level active management and integration of flexibility. Recommendations for developing studies in this open field of research have been pointed out by recent reviews on the subject [6].

In addition, in the smart grid context, uncertainty plays an important role in the process of decision making. One common practice to facilitate these optimization processes is Stochastic Programming (SP), which typically aims to optimize over the expectation of a number of predefined scenarios [7]. In this group, a selection of scenarios with a certain probability must be predefined and embedded into the optimization formulation. In this group of proposals, two-stage optimization problems can be found [3], [8]-[10] to identify an expected operation value. The idea is to define a first stage (or here-and-now decision) with variables and decisions that usually correspond to the committed energy purchases in the DA market and the generation commitment for conventional generation. After this, a set of second (or recourse) decisions are made, according to the realizations of the uncertain variables. For the analyzed cases, the second-stage decisions are related to the settings of the controllable devices, such as batteries, heat storage, combined heat and power (CHP) plants and active demand. This approach also has the advantage of simplicity in its modeling, with a trade-off of increasing the number of variables depending on the scenarios to be analyzed in the second stage.

An alternative approach which has gained substantial attention in recent years is Robust Optimization (RO) [11], which is an interval based optimization method. $\mathrm{RO}$ does not require knowledge of the Probability Density Function (PDF) of the uncertain variables, but instead requires moderate information, i.e. an uncertainty set for each uncertain variable. RO will provide a robust optimal solution that is feasible (immunized) within the confidence interval. Although there is still little research on exploiting RO capabilities in residential storagebased energy systems, work has begun to be published in recent years, specifically related to medium-size DG/microgrid management. For instance, [12] presents a model for strategic bidding in energy and ancillary markets for a microgrid consisting of RES, a microturbine (MT), and a battery, in which RO is used to include RES uncertainty and SO is used to tackle price uncertainty. For bidding purposes in dayahead and real-time markets, reference [13] proposes a hybrid stochastic/robust approach, in which RO captures uncertainty in real-time prices, while stochastic optimization is used to include wind and PV scenarios. Both approaches ( [12], [13]) assume deterministic demand.

Following in the path of the mentioned literature, this research intends to join flexibilities of two types, i.e. the flexibility given by home-level microgrid devices and their management, and the flexibility needed by a local DSO/utility at the Point of Common Coupling (PCC). Hence, the objective of the present paper is to contribute with a framework to optimally manage residential flexibilities by integrating several aspects such as: electric/thermal load and storage, home/building level management, uncertainties in PV, load and energy prices, and local DSO signals. These aspects are analyzed from the standpoint of an aggregator participating in the day-ahead and imbalance markets and taking into account DSO flexibility requests. In particular, to the best of the authors' knowledge, home-level management with load, RES and price uncertainty has not been addressed in combination with utility grid requirements via active power management. Additionally, the work presented here was performed within the EU Horizon 2020 project SENSIBLE (Storage Enabled Sustainable Energy for Buildings and Communities), as a part of the use case "Flexibility and demand side management in market participation".

The problem is cast into a hybrid stochastic/robust optimization model to minimize costs, where the decisions correspond to the DA import/export energy, the imbalances, and the setpoints of home devices. This is to overcome the realizations of PV/load modeled via $\mathrm{RO}$ and prices modeled with scenarios in order to comply with electrical/thermal constraints and gridlevel flexibility requirements. Section II shows the framework of the proposed model. Next, section III presents the details of the mathematical formulation. Section IV presents the results of the proposed approach and concluding remarks are outlined in $\mathrm{V}$.

\section{DESCRIPTION OF THE TEST CASE}

The proposed community microgrid is composed by a set of houses from the Evora European demonstrator, some of which are equipped with solar panels, li-ion batteries and heat-storage devices. The considered system is connected to the main grid. Each household comprises a total electrical base load to be supplied and a thermal load that has to be met by an EWH, which also stores energy in the form of heat.

The flexibility aggregator participates in the day-ahead and imbalance markets to optimize its portfolio, while complying with physical microgrid limitations and the signals sent from the local DSO regarding flexibility products for load management. Bidirectional power flows can occur at the PCC with the local DSO grid. The DSO flexibility requirements in the PCC are of two types: a) power flexibility, which imposes limits or certain power exchange patterns according to grid needs at specific times; b) ramping flexibility, which limits the net load ramping seen by the local DSO (see upper part of figure 1).

The DSO and the aggregator establish communication to send/receive information, while only the aggregator has communication and control capabilities with devices at home level. We suppose the existence of the necessary IT and communication platform, so that the aggregator controls devices at the home level and decides over their set-points.

Decisions regarding DSO flexibility requirements and products at the PCC correspond to grid analysis concerning voltage 
limits, congestion management, equipment degradation, and scheduled maintenance, among others. The definition of these requirements and the market design of the payment of this service are out of the scope of this paper.

To predict the electrical demand of individual households, the model uses the demand during the previous week and the outside temperature predicted for the next day and then performs quantile smoothing spline fitting. After quantile regression, a set of forecast quantiles is obtained. Instead of a single-point value, $10 \%, 20 \%, \ldots, 90 \%$ values are obtained and respectively associated with a $10 \%, 20 \%, \ldots, 90 \%$ chance of measuring lower actual demand at the instant predicted. For PV power forecasts, a quantile approach is also used, using a conditional Kernel estimator based on irradiance-level forecasts. After this, quantiles (10\%-90\%) and the median $(50 \%)$ for both demand and PV production are obtained in order to be used as inputs for the model. For further details readers are advised to review reference [14].

Electricity prices are taken from the ENTSOE database [15], using data from the last three months prior to the day of dispatch. To form the training set, the data during this period on the same weekday are considered. This is done to consider a realistic case in which an aggregator, when defining dayahead purchases, does not have the settled prices. With this input, a Kernel Density Estimation (KDE) is performed to obtain a non-parametric density function of prices. To perform the KDE, the Python package scikit-learn [16] was used.

After the KDE is performed, random sampling is performed to create price scenarios. Given that a large number of scenarios may lead to high computational times, a scenario reduction technique is implemented. In this work, backward reduction algorithm based on Kantorovich Distance (KD) [17] is used to obtain a reduced representative set.

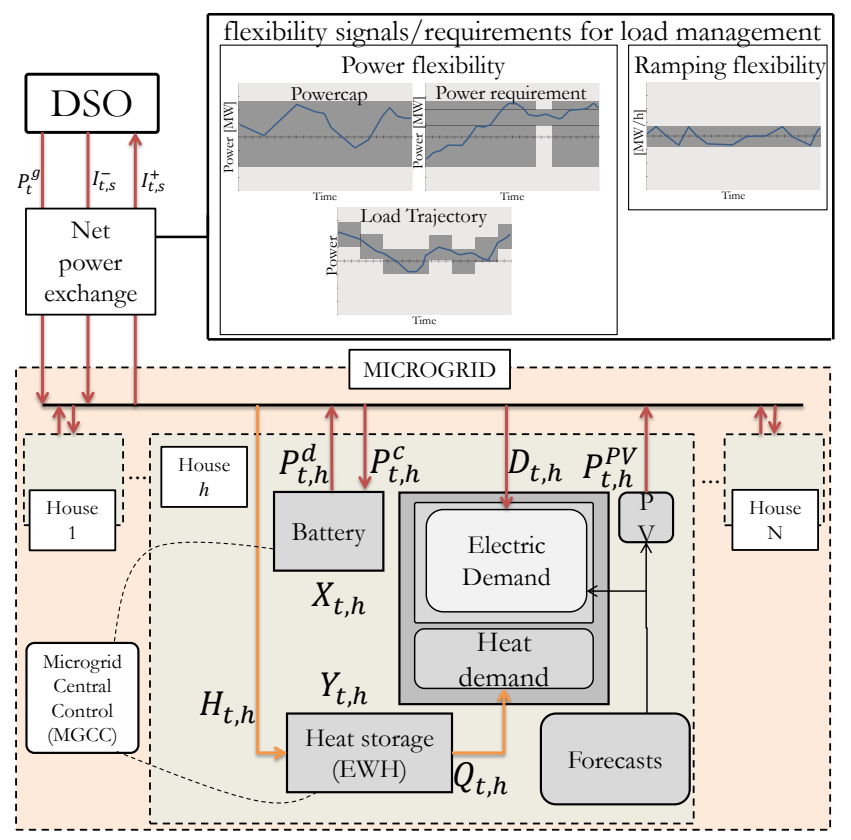

Fig. 1. Schematic diagram of the proposed framework

\section{MATHEMATICAL MODEL}

The proposed hybrid stochastic/robust optimization model minimizes the DA expected operation cost, in which the cost is associated with the day-ahead net exchange $\left(P_{t}^{g}\right)$ expected costs and the import/exports $\left(I_{t, s}^{-} / I_{t, s}^{+}\right)$imbalance as expressed in equation (1), where subscripts $t, s$ and $h$ index time step, scenario and household, respectively. Parameters $\pi_{t}, \mu_{t}^{-},-\mu_{t}^{+}$, represent respectively spot price, negative imbalance cost, and positive imbalance cost. In addition, $p_{s}$ is the probability of scenario $s$.

$$
\operatorname{minimize} \sum_{s=1}^{S} p_{s}\left\{\sum_{t=1}^{T}\left[\pi_{t, s} P_{t}^{g}+\mu_{t}^{-} I_{t, s}^{-}-\mu_{t}^{+} I_{t, s}^{+}\right]\right\}
$$

Next, the operational constraints describe the behavior of the devices and balance the load of the proposed system. Constraint (2) represents the power balance and includes the robust counterpart for including electrical demand and PV uncertainty in terms of net load (demand minus PV). This constraint includes the robust parameter $\Gamma_{t}^{D}$ for controlling conservatism of net demand uncertainty. Constraints (3)-(4) are additional constraints of the robust counterpart that result from strong duality theorem.

$$
\begin{gathered}
P_{t}^{g}+I_{t, s}^{-}-I_{t, s}^{+}+\Delta t \sum_{h=1}^{N} P_{t, h}^{d}-P_{t, h}^{c}-H_{t, h}= \\
D_{t}^{n e t}+q_{t}^{D}+\Gamma_{t}^{D} z_{t}^{D}, \forall t, \forall s \\
z_{t}^{D}+q_{t}^{D} \geq \frac{1}{2}\left(\bar{D}_{t}^{\text {net }}-\underline{D}_{h}^{\text {net }}\right) y_{t}^{D}, \forall t \\
z_{t}^{D}, q_{t}^{D} \geq 0, y_{t}^{D} \geq 1, \forall t
\end{gathered}
$$

Constraints (5) and (10) describe the energy state for batteries and the TES, respectively, and $X_{t, s, h}, Y_{t, s, h}$ represent the stored energy of these devices. Parameters $\eta^{c}$ and $\eta^{d}$ are the charging and discharging power of the battery. Constraints (7)(8) ensure that charging and discharging of the batteries do not occur at the same time. Constraints (10)-(12) are the resulting robust counterpart of considering uncertainty in thermal load, with $\Gamma_{t}^{t h}$ controlling thermal load conservatism.

$$
\begin{gathered}
X_{t, h}=X_{t-1, h}+\eta^{c} P_{t-1, h}^{c}-P_{t-1, h}^{d} / \eta^{d}, \forall t, t \neq 1, \forall h \\
X_{1, h}=X_{T, h}, \forall h \\
0 \leq P_{t, h}^{c} \leq \bar{P}_{h}^{c} \cdot u_{t, h}, u_{t, h} \in\{0,1\}, \forall t, t \neq 1, \forall h \\
0 \leq P_{t, h}^{d} \leq \bar{P}_{h}^{d} \cdot\left(1-u_{t, h}\right), \forall t, \forall h \\
\underline{X}_{h} \leq X_{t, h} \leq \bar{X}_{h}, \forall t, \forall h \\
Y_{t, h}=Y_{t-1, h}+\Delta t H_{t-1, h}-Y_{t-1, h} / R_{h} C_{h}- \\
\Delta t\left(\hat{Q}_{t-1, h}+q_{t-1, h}^{t h}+\Gamma_{t-1, h}^{t h} z_{t-1, h}^{t h}\right), \forall t, \forall h \\
z_{t, h}^{t h}+q_{t, h}^{t h} \geq \frac{1}{2}\left(Q_{t, h}^{90 \%}-Q_{t, h}^{10 \%}\right) y_{t, h}^{t h}, \forall t, \forall h \\
z_{t, h}^{t h}, q_{t, h}^{t h} \geq 0, y_{t, h}^{t h} \geq 1, \forall t, \forall h \\
Y_{1, h}=Y_{T, h}, \forall h \\
\underline{Y}_{t, h} \leq Y_{t, h} \leq \bar{Y}_{t, h}, \forall t, \forall h \\
0 \leq H_{t, h} \leq \bar{H}_{t, h}, \forall t, \forall h
\end{gathered}
$$


The grid flexibility constraints describe the requirements or signals sent by the utility grid, in terms of net ramping $\left(R_{t}\right)$ and net allowed power exchanges. Constraints (16)-(19) model the ramping flexibility, which represents the maximum allowed net power change in consecutive time steps. Constraint (16) ensures that the day-ahead commitment respects maximum ramping, and in the same way, constraint (18) also includes negative and positive imbalance exchanges in each scenario. Constraints (17), (19) ensure continuity between the last and first time steps of the operation day. Constraints (20)-(21) model the maximum allowed power flexibility. Parameters $P_{t}^{P C C_{\min }} / P_{t}^{P C C_{\max }}$ are the $\mathrm{min} / \mathrm{max}$ net power in the PCC.

These last two constraints are general enough to represent any DSO signal in terms of net power exchange, as shown in figure 1 (powercap, power requirement, load trajectory).

$$
\begin{gathered}
\left|P_{t}^{g}-P_{t-1}^{g}\right| \leq R_{t}, \forall t, t \neq 1 \\
\left|P_{1}^{g}-P_{T}^{g}\right| \leq R_{t} \\
\left|P_{t}^{g}+I_{t, s}^{-}-I_{t, s}^{+}-\left(P_{t-1}^{g}+I_{t-1, s}^{-}-I_{t-1, s}^{+}\right)\right| \leq R_{t}, \forall t, t \neq 1, \forall s \\
\left|P_{1}^{g}+I_{1, s}^{-}-I_{1, s}^{+}-\left(P_{T}^{g}+I_{T, s}^{-}-I_{T, s}^{+}\right)\right| \leq R_{t}, \forall s \\
P_{t}^{P C C_{\min }} \leq P_{t}^{g} \leq P_{t}^{P C C_{\max }}, \forall t \\
P_{t}^{P C C_{\min }} \leq P_{t}^{g}+I_{t, s}^{-}-I_{t, s}^{+} \leq P_{t}^{P C C_{\max }}, \forall t, \forall s
\end{gathered}
$$

The previous model is the complete hybrid stochastic/robust problem. When only one scenario for price is considered and $\Gamma_{t}^{D}=\Gamma_{t}^{t h}=0$, the model is the deterministic equivalent.

The next section describes and presents the results obtained for deterministic and hybrid cases.

\section{RESULtS}

\section{A. Input data}

The proposed algorithm is coded in Python. The electric base load is generated following the logic explained in section II for the 25 houses in the Evora demonstrator. The location of the HEMS in the real-life distribution network and the resources present in each house are shown in figure 2 . The 25 houses correspond to two different LV rural networks, A and $\mathrm{B}$, comprising 16 and 9 households respectively and containing the distribution of resources shown in the figure. In total, the houses feature $25 \mathrm{PV}$ panels, 16 BESSs and $15 \mathrm{EWHs}$. The test case is composed by only the HEMS and the control capabilities that an aggregator has over the device settings. A normalized thermal load pattern is taken from [18].

The charging and discharging efficiency of the batteries is assumed to be $95 \%$. 15 batteries are rated $3 \mathrm{~kW} / 3.3 \mathrm{kWh}$, and the remaining battery is a $10 \mathrm{~kW} / 20 \mathrm{kWh}$ device. All $\mathrm{PV}$ panels are rated $1.5 \mathrm{kWp}$. The rated power/energy for all EWH is $1.5 \mathrm{~kW} / 3 \mathrm{kWh}$ and thermal resistance/capacitance are $568\left({ }^{\circ} \mathrm{C} / \mathrm{kW}\right) / 0.3483\left(\mathrm{kWh} /{ }^{\circ} \mathrm{C}\right)$ in line with [3].

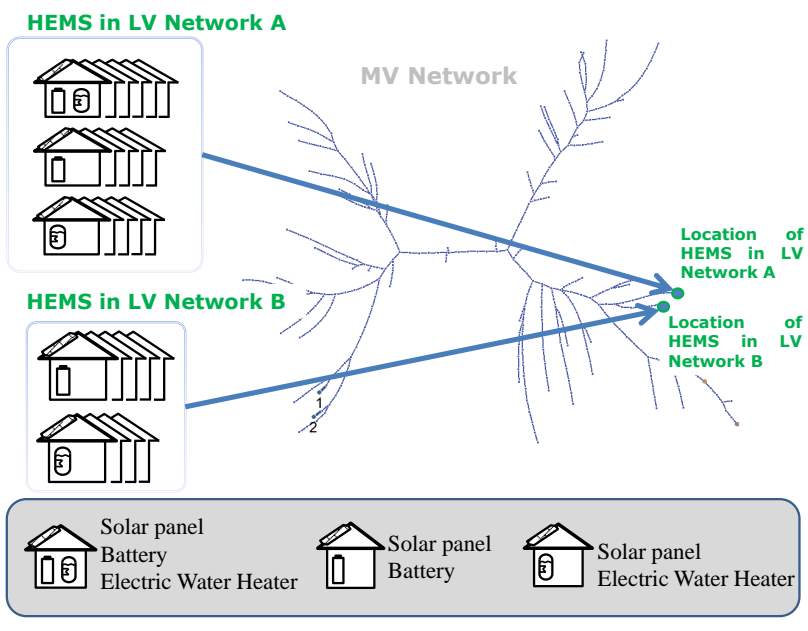

Fig. 2. Composition and location of the proposed 25-household HEMS

\section{B. Test 1: Deterministic without DSO flexibility requirements}

First, a deterministic analysis without considering DSO flexibility requirements is carried out to determine the impact on the cost, when using different sources of home-level flexibility. The simulation in which no thermal storage or batteries are considered is used as the base case for comparison purposes. This base case supposes only PV and participation in the day-ahead market to cover energy needs of the HEMS. The day-ahead operation cost for the base case is: $€ 19.41$. Three cases are run; case 1: only TES; case 2: only batteries; case 3: batteries and TES. The costs for each of the four cases are $€ 19.28$, $€ 18.67$ and $€ 18.54$, respectively. When all types of home flexibility are used, savings reach $4.5 \%$ when the operation cost is compared to the base case.

From figure 3 it can be seen that inclusion of home flexibilities tends to increase the variability of net power exchange so as to manage devices in order to find a minimum cost. For instance, the base case $(-\bullet)$ and case $1(--)$ show moderate peaks, and extreme values occur at hours 9 and 17 . With this energy commitment, operation costs are guaranteed to be minimum. However, when all types of flexibility are included, such as TES and batteries (case $3\left(\star_{-}\right)$), interactions among devices increase and energy commitment also changes in order to exploit storage capabilities. During hours 9, 14, 17 and 22, the net exchange increases, reaching 90 $\mathrm{kW}$. This full exploitation of flexibilities without considering upstream effects could jeopardize the utility grid, hence, it becomes important to include grid flexibility requirements at the PCC and analyze any impacts on the microgrid operation, as described in the next subsection.

\section{Test 2: Hybrid stochastic/robust model with DSO flexibility requirements}

The hybrid stochastic-robust optimization model described in (1)-(21) is solved for the price scenarios described in the previous section, considering all flexibilities provided by the microgrid and also including different values for grid flexibility requirements $\left(P_{t}^{P C C_{\max }}\right.$ and $\left.R_{t}\right)$. When DSO flexibility requirements are present in the model, the energy 


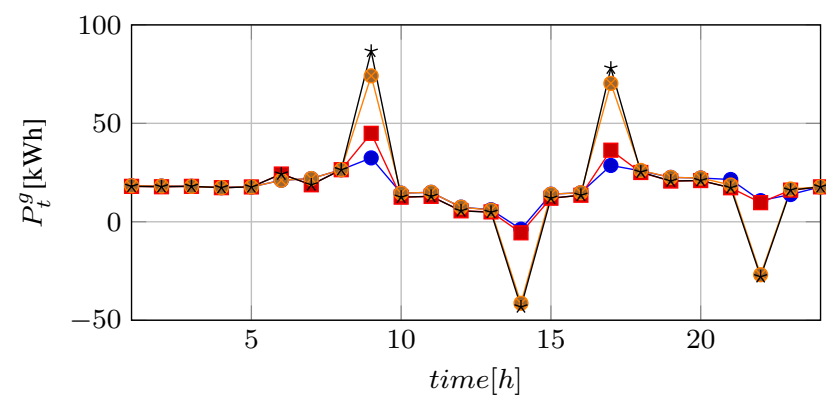

Fig. 3. Day-ahead committed energy for base case $(-\bullet)$, case $1(-\longrightarrow)$, case $2(-)$ and case $3(-*)$.

committed and the devices' scheduling must adjust to comply with maximum net power and ramping constraints. In this hybrid case, the operation cost without considering flexibility constraints is $€ 24.92$ (unconstrained case). Table I shows the costs obtained for different combinations of $P_{t}^{P C C_{\max }}$ and $R_{t}$. For instance, when ramping is limited to $0.01 \mathrm{MW} / \mathrm{h}$ and maximum power to $0.03 \mathrm{MW}$, the operation cost of the HEMS is $€ 25.49$, which represents a $2.3 \%$ increase with respect to the unconstrained case. This means that if the DSO sends this signal, the HEMS aggregator would have to adjust its settings and incur extra costs to satisfy the DSOs needs.

The different operation points lead to different committed energy on the day-ahead market. For example, if $R_{t}$ is kept constant at $0.03 \mathrm{MW} / \mathrm{h}$ and $P_{t}^{P C C_{\max }}$ assumes different values, the energy that should be exchanged in the wholesale market is shown in figure 4 . While the changes in the operation cost range between $€ 24.97$ and $€ 25.40$, the changes in committed energy are more evident so as to comply with the different values of maximum power.

TABLE I

OPERATION COSTS FOR DIFFERENT VALUES OF FLEXIBILITY REQUIREMENTS

\begin{tabular}{c|c|c|c} 
& \multicolumn{3}{|c}{$P_{t}^{P C C_{\max }}$} \\
$R_{t}$ & $0.03 \mathrm{MW}$ & $0.05 \mathrm{MW}$ & $0.07 \mathrm{MW}$ \\
\hline \hline $0.01 \mathrm{MW} / \mathrm{h}$ & 25.49 & 25.20 & 25.20 \\
\hline $0.03 \mathrm{MW} / \mathrm{h}$ & 25.40 & 24.99 & 24.97 \\
\hline $0.06 \mathrm{MW} / \mathrm{h}$ & 25.39 & 24.98 & 24.94 \\
\hline
\end{tabular}

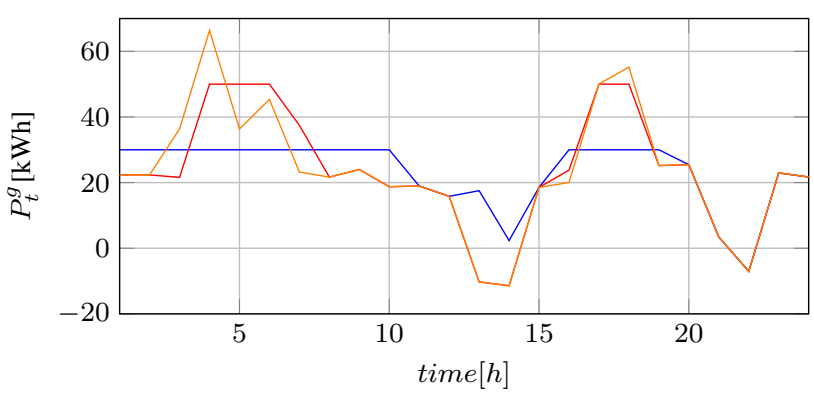

Fig. 4. Day-ahead committed energy for $P_{t}^{P C C_{\max }}=0.03 \mathrm{MW}(-)$, $P_{t}^{P C C_{\max }}=0.05 \mathrm{MW}(-), P_{t}^{P C C_{\max }}=0.07 \mathrm{MW}(-)$ when constant $R_{t}=0.03 \mathrm{MW} / \mathrm{h}$

The day-ahead energy commitment for different allowed ramping values and fixed $P_{t}^{P C C_{\max }}=0.05 M W$ is shown in figure 5. In this case, it can be seen that peaks are shaved at the level of $50 \mathrm{~kW}$, and that $R_{t}=0.06 M W(--)$ allows more unconstrained ramping, as is the case for time frames 13h-14h-15h and 21h-22h-23h. In general, each case leads to a different operation point and the operation cost ranges from $€ 24.98$ to $€ 25.20$. It can be seen that operational costs for the flexibility aggregator increase when flexibility needs from utilities narrow their margins, which in turn signals the remuneration that an aggregator should receive for providing flexibility services to the grid.

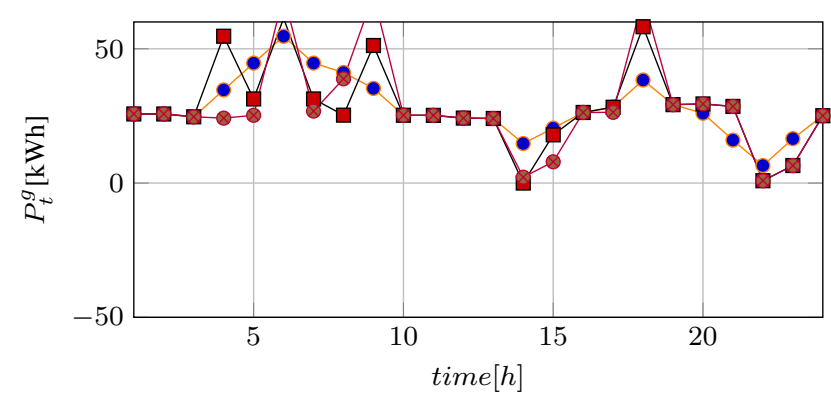

Fig. 5. Day-ahead committed energy for $R_{t}=0.01 \mathrm{MW} / \mathrm{h}(-\bullet), R_{t}=$ $0.03 \mathrm{MW} / \mathrm{h}(-\square), R_{t}=0.06 \mathrm{MW} / \mathrm{h}\left(-{ }^{-}\right)$when constant $P_{t}^{P C C_{\max }}=$ $0.05 \mathrm{MW}$

In addition, the signals from the utility force a reshaping of the net load at the PCC, hence leading to an adjustment of the devices' settings.

\section{Bidding on the local market}

1) Demand bidding curves: Figure 6 shows the demand bidding curves for two different hours. These piece-wise curves show the hourly bids made by the aggregator for economical operation when only wholesale market participation is allowed and no other local flexibility market exists. The curves are built using the hybrid stochastic/robust approach by varying the day-ahead energy price at the specific hour. The variations range from the $10 \%$ to the $90 \%$ percentile of the price predicted by the KDE. It is important to note that bids for hour 21 have higher associated prices given the history of prices for these night-time frames

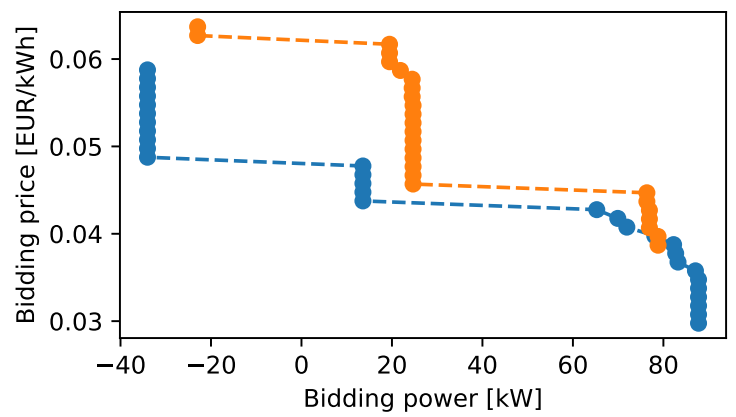

Fig. 6. Demand bidding curves for $\mathrm{t}=14 \mathrm{~h}$ (green), $\mathrm{t}=21 \mathrm{~h}$ (orange)

2) Local flexibility supplying curves: If a local market is established to define the appropriate flexibility prices to be provided by the aggregator at the PCC, then the construction of 
supplying bidding curves could give an idea of the appropriate remuneration that the aggregator should receive for modifying the net power exchange coming from a DSO signal. This option is shown in figure 7 . These curves measure the extra cost of the aggregator's operation when deviating from the committed day-ahead energy. Hence, this price is the minimum that should be paid to the aggregator if the DSO requires flexibility.

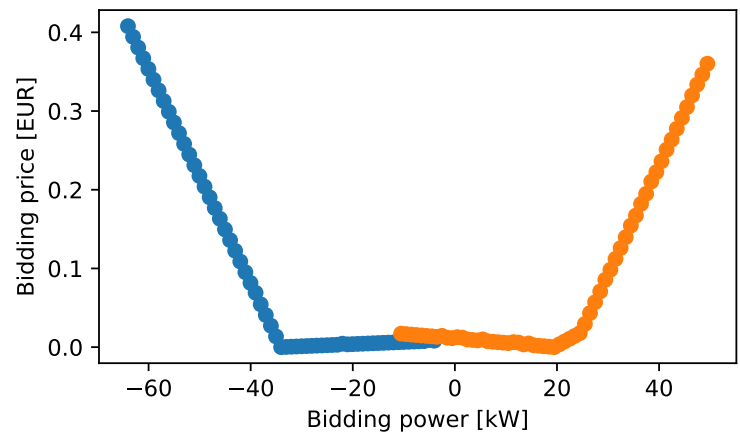

Fig. 7. flexibility supply bidding curves for $\mathrm{t}=14 \mathrm{~h}($ green $), \mathrm{t}=21 \mathrm{~h}$ (orange)

For instance, the scheduled power purchase for $\mathrm{t}=21$ (orange) is $19.5 \mathrm{~kW}$, hence if this is the flexibility required by the DSO, there is no deviation for the aggregator and no remuneration takes place (zero bidding price). However, if flexibility starts to increase, it can be seen that payments to the aggregator should be made, given the required deviation from the original scheduling.

\section{CONCLUSiOns}

The proposed approach presents a mathematical model to include local flexibility constraints in the form of maximum allowed net power exchange at the PCC and also ramping limits. The simulations analyze different values and combinations of flexibility needs to determine the appropriate changes in the aggregator's schedule to achieve minimum operation costs while complying with the DSO's flexibility constraints.

For the stochastic/robust case and flexibility values analyzed, the operation cost for the aggregator increases up to $2.3 \%$ with respect to a base case in which no DSO flexibility signals are considered. This information is useful to determine potential remuneration for the aggregator for providing local flexibility services, given that scheduling of resources has to change to provide the needed flexibility.

These adjustments in the operation of HEMS allow an aggregator to participate in the electricity market while cooperating with the local DSO to enhance network operation and promote decentralization of the electrical system.

\section{REFERENCES}

[1] B. Zhou, W. Li, K. W. Chan, Y. Cao, Y. Kuang, X. Liu, and $\mathrm{X}$. Wang, "Smart home energy management systems: Concept, configurations, and scheduling strategies," Renewable and Sustainable Energy Reviews, vol. 61, pp. 30 - 40, 2016. [Online]. Available: http://www.sciencedirect.com/science/article/pii/S1364032116002823
[2] A. Majzoobi and A. Khodaei, "Application of microgrids in supporting distribution grid flexibility," IEEE Transactions on Power Systems, vol. PP, no. 99, pp. 1-1, 2016.

[3] N. Good, E. Karangelos, A. Navarro-Espinosa, and P. Mancarella, "Optimization under Uncertainty of Thermal Storage-Based Flexible Demand Response with Quantification of Residential Users' Discomfort," IEEE Transactions on Smart Grid, vol. 6, no. 5, pp. 2333-2342, 2015.

[4] N. Holjevac, T. Capuder, and I. Kuzle, "Adaptive control for evaluation of flexibility benefits in microgrid systems," Energy, vol. 92, Part 3, pp. 487 - 504, 2015, sustainable Development of Energy, Water and Environment Systems.

[5] B. Morvaj, K. Knezovi, R. Evins, and M. Marinelli, "Integrating multidomain distributed energy systems with electric vehicle $\{P Q\}$ flexibility: Optimal design and operation scheduling for sustainable low-voltage distribution grids," Sustainable Energy, Grids and Networks, vol. 8, pp. $51-61,2016$.

[6] C. Eid, P. Codani, Y. Perez, J. Reneses, and R. Hakvoort, "Managing electric flexibility from distributed energy resources: A review of incentives for market design," Renewable and Sustainable Energy Reviews, vol. 64, pp. 237 - 247, 2016.

[7] J. R. Birge and F. Louveaux, Introduction to Stochastic Programming, 2nd ed. New York, NY, USA: Springer-Verlag, 2011.

[8] Z. fu Tan, L. wei Ju, H. huan $\mathrm{Li}$, J. yu $\mathrm{Li}$, and $\mathrm{H}$. juan Zhang, "A two-stage scheduling optimization model and solution algorithm for wind power and energy storage system considering uncertainty and demand response," International Journal of Electrical Power Energy Systems, vol. 63, pp. 1057 - 1069, 2014. [Online]. Available: http://www.sciencedirect.com/science/article/pii/S0142061514004190

[9] D. T. Nguyen and L. B. Le, "Optimal bidding strategy for microgrids considering renewable energy and building thermal dynamics," IEEE Transactions on Smart Grid, vol. 5, no. 4, pp. 1608-1620, July 2014.

[10] W. Su, J. Wang, and J. Roh, "Stochastic energy scheduling in microgrids with intermittent renewable energy resources," IEEE Transactions on Smart Grid, vol. 5, no. 4, pp. 1876-1883, July 2014

[11] D. Bertsimas and M. Sim, "Robust discrete optimization and network flows," Math. Program., Ser. B, vol. 98, no. 1-3, pp. 49-71, 2003.

[12] J. Wang, H. Zhong, W. Tang, R. Rajagopal, Q. Xia, C. Kang, and Y. Wang, "Optimal bidding strategy for microgrids in joint energy and ancillary service markets considering flexible ramping products,' Applied Energy, vol. 205, pp. 294 - 303, 2017. [Online]. Available: http://www.sciencedirect.com/science/article/pii/S0306261917309212

[13] G. Liu, Y. Xu, and K. Tomsovic, "Bidding strategy for microgrid in day-ahead market based on hybrid stochastic/robust optimization," IEEE Transactions on Smart Grid, vol. 7, no. 1, pp. 227-237, Jan 2016.

[14] A. Gerossier, R. Girard, G. Kariniotakis, and A. Michiorri, "Probabilistic day-ahead forecasting of household electricity demand," in In revision CIRED 2017, June 2017.

[15] "Entsoe transparency. central collection and publication of electricity generation, transportation and consumption data and information for the pan-european market, dayahead prices," https://transparency.entsoe.eu/transmissiondomain/r2/dayAheadPrices/show, accessed: 2018-01-25.

[16] F. Pedregosa, G. Varoquaux, A. Gramfort, V. Michel, B. Thirion, O. Grisel, M. Blondel, P. Prettenhofer, R. Weiss, V. Dubourg, J. Vanderplas, A. Passos, D. Cournapeau, M. Brucher, M. Perrot, and E. Duchesnay, "Scikit-learn: Machine learning in Python," Journal of Machine Learning Research, vol. 12, pp. 2825-2830, 2011.

[17] N. M. M. Razali and A. H. Hashim, "Backward reduction application for minimizing wind power scenarios in stochastic programming," in 2010 4th International Power Engineering and Optimization Conference (PEOCO), June 2010, pp. 430-434.

[18] C. Marnay, G. Venkataramanan, M. Stadler, A. Siddiqui, R. Firestone, and B. Chandran, "Optimal Technology Selection and Operation of Commercial- Building Microgrids - LBNL No. 62315," IEEE Trans. Power Syst., vol. 23, no. 3, pp. 1-10, 2007. 